\title{
ROLE OF RENIN-ANGIOTENSIN SYSTEM IN
}

\section{EXPERIMENTAL HYPERTENSION IN RATS:}

\author{
Plasma Renin and Hypotensive Effect of Angiotensin II Antagonist
}

\author{
JiN YAmamoto, M.D.
}

\begin{abstract}
The hypotensive effect of 1-Sar-8-Ile-angiotensin II, a competitive antagonist of angiotensin II, and the pre-infusion level of plasma renin concentration were examined in conscious rats with various types of hypertension to assess the role of the renin-angiotensin system in the pathogenesis of experimental hypertension. The infusion of 1-Sar-8-Ile-A II $(0.64 \mu \mathrm{g} / \mathrm{min}$ or $3.2 \mu \mathrm{g} / \mathrm{min})$ caused a significant fall in blood pressure in two-kidney Goldblatt rats (4-5 weeks after clipping) and 7-8-month-old stroke-prone spontaneously hypertensive rats (SHR), while it was statistically ineffective in one-kidney Goldblatt rats (4-5 weeks after clipping), one- and two-kidney Loomis rats ( 2 and 4-5 weeks after induction), 5-month-old stroke-prone SHR and 2-, 5-, 8- and 14-month-old stroke-resistant SHR. A significant correlation between plasma renin concentration and the susceptibility to the antagonist was observed in Goldblatt rats and stroke-prone SHR, but not in Loomis rats and stroke-resistant SHR. Some groups of animals which had not responded to the original infusion of 1-Sar-8-Ile-A II were infused again with the same antagonist in a furosemide-induced volume-depleted state, in which plasma renin level was prominently elevated in all rats and angiotensin-II dependency of blood pressure was disclosed except in the 8-month-old stroke-resistant SHR. These data suggest that the renin-angiotensin system is critically involved in the two-kidney Goldblatt rats and the 7-8-month-old strokeprone SHR, but that it is much less important in other hypertensive rats and other factors would be involved especially in case of stroke-resistant SHR.
\end{abstract}

$\mathbf{I}^{\mathrm{N}}$ spite of extensive studies, the role of the renin-angiotensin system in the pathogenesis of human and experimental hypertension has not been clarified yet. The recent development of agents which block either the action or the formation of angiotensin II (A II) has pro-

\footnotetext{
Key Words:

1-Sar-8-Ile-angiotensin II

Plasma renin concentration

One-kidney type

Two-kidney type

Goldblatt hypertension

Loomis hypertension

Stroke-prone spontaneously hypertensive rat

Stroke-resistant spontaneously hypertensive rat

Furosemide
}

vided a new approach to the investigation of this problem! Among such agents, a synthetic antagonist analogous to A II is considered to be the most useful because of its superiority in both specificity and potency. In the present experiments, the hypotensive effect of 1-Sar-8-Ile-A II, a competitive antagonist of $\mathrm{A} \mathrm{II}, 2,3$ was examined in relation to the pre-existing level of plasma renin concentration (PRC) in various types of hypertension in rats. A preliminary report of this study was previously presented.,5

\section{MATERIALS AND METHODS}

Animals and Induction of Hypertention Female rats with Goldblatt hypertension or Loomis

(Received on July 7, 1976; Accepted on January 28, 1977)

The 3rd Division, Department of Internal Medicine, Faculty of Medicine, Kyoto University, Kyoto, Japan 


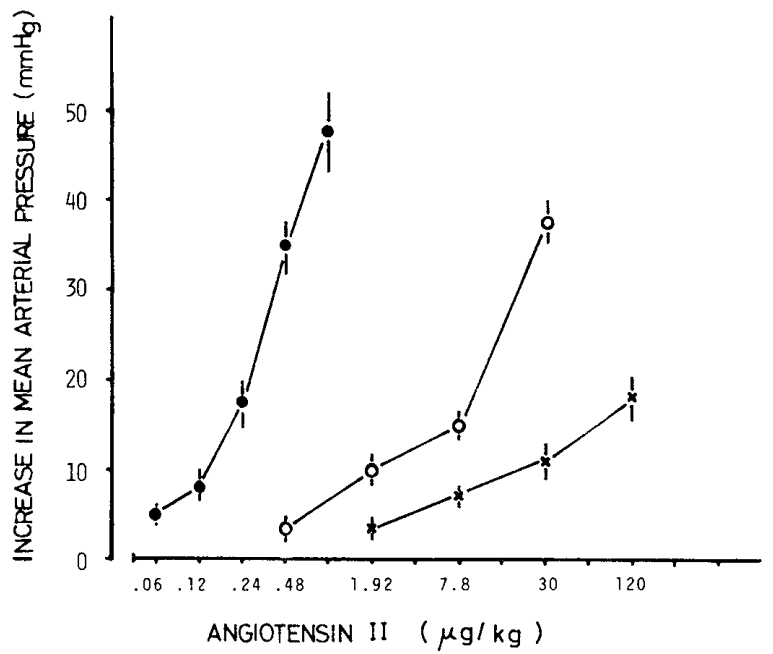

Fig.1. Dose response curves for angiotensin II in conscious normal rats. Closed circles represent control values, open circles represent values obtained during the infusion of 1-Sar-8-Ile-A II $(0.64 \mu \mathrm{g} / \mathrm{min}, \quad 2.1 \mu \mathrm{g} / \mathrm{kg} / \mathrm{min})$, and crosses represent values during the infusion of 1-Sar-8Ile-A II $(3.2 \mu \mathrm{g} / \mathrm{min}, 10.5 \mu \mathrm{g} / \mathrm{kg} / \mathrm{min}$.). Values are mean \pm S.E.
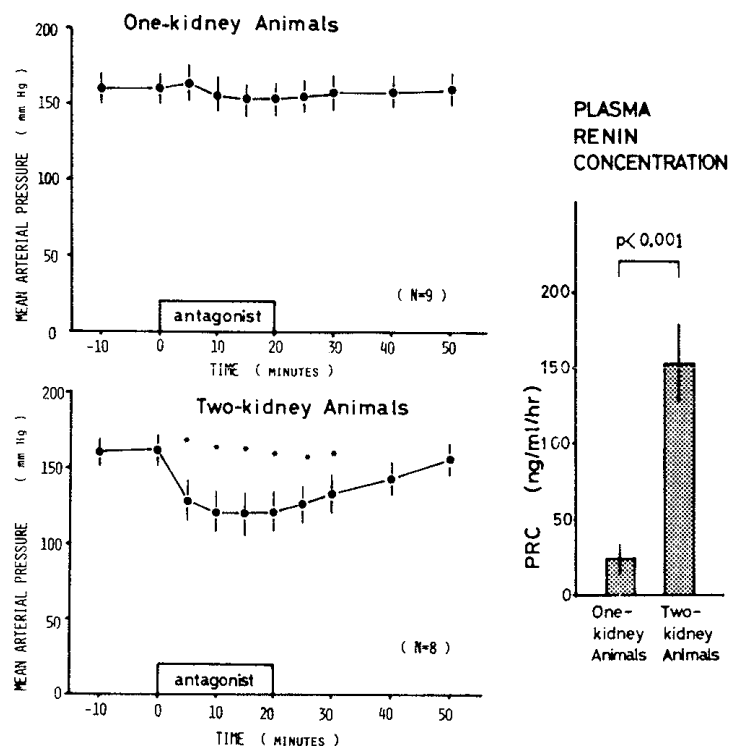

Fig. 2. The effect of 1-Sar-8-Ile-A II on the blood pressure (left) and the pre-infusion levels of plasma renin concentration (right) in conscious rats with Goldblatt hypertension 4-5 weeks after clipping. The one-kidney animals (left upper) were infused with $3.2 \mu \mathrm{g} / \mathrm{min}$ of the antagonist, while the two-kidney animals (left lower) were infused with $0.64 \mu \mathrm{g} / \mathrm{min}$ of the antagonist. Values are mean \pm S.E. ${ }^{*} p<0.01$, significance of difference in comparison to the control level of the blood pressure.
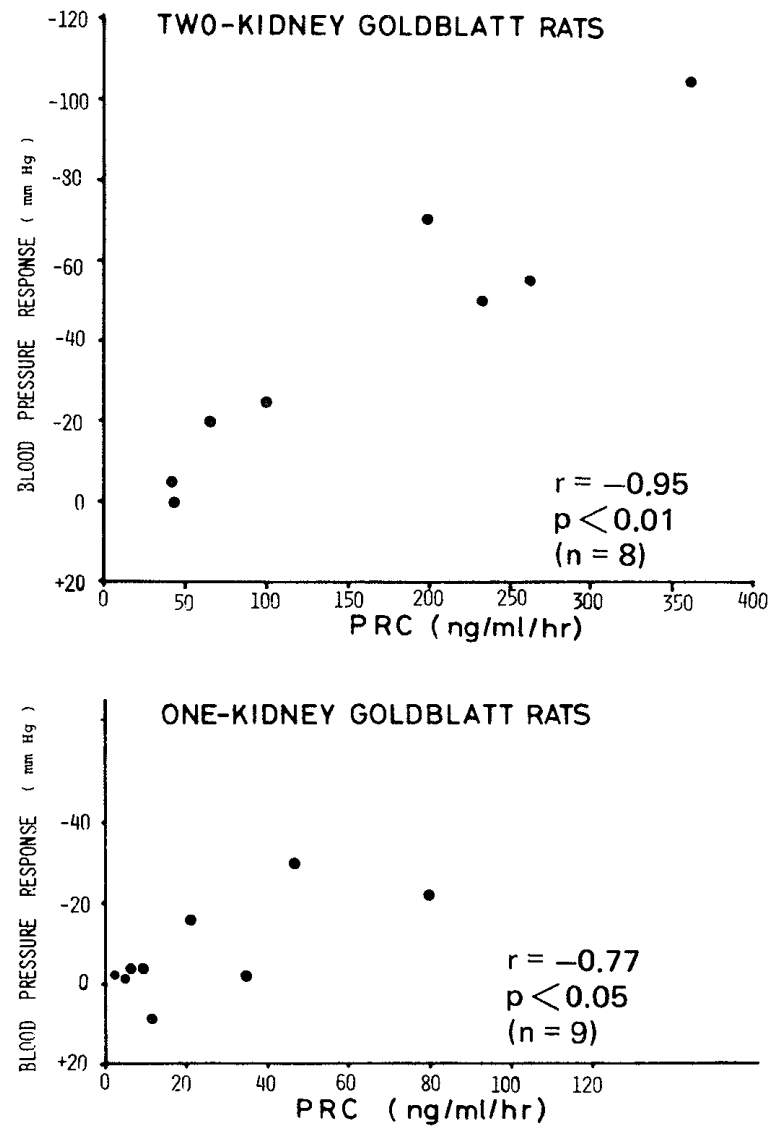

Fig.3. Correlation between the pre-infusion level of plasma renin concentration (PRC) and the blood pressure response to the infusion of 1-Sar-8-Ile-A II in the one-kidney (lower) and the two kidney (upper) Goldblatt rats.

hypertension, 6 and males of the stroke-prone and stroke-resistant spontaneously hypertensive rats (SHRSP and SHRSR) ${ }^{7}$ and Wistar Kyoto rats (WK) were used in this study. Controls for Loomis hypertension were sham-operated rats.

Goldblatt hypertension was induced in female Wistar rats weighing $170-190 \mathrm{~g}$ by placing a silver clip $(2.0 \mathrm{~mm} \times 0.2 \mathrm{~mm}$ i.d. $)$ on the left renal artery. The contralateral kidney was removed in one group (one-kidney type), while it was left untouched in the other group (twokidney type). Infusion experiments were carried out 4-5 weeks after the clipping.

Loomis hypertension was induced in female Wistar rats weighing $180-230 \mathrm{~g}$ by ligating the posterior branch of the left renal artery with (one-kidney type) or without (two-kidney type) contralateral nephrectomy. One group of rats were subjected to the experiment 2 weeks after and the others 4-5 weeks after the operation.

Infusion experiments were also performed on SHRSP aged 5 months (body weight 280-322 g, 

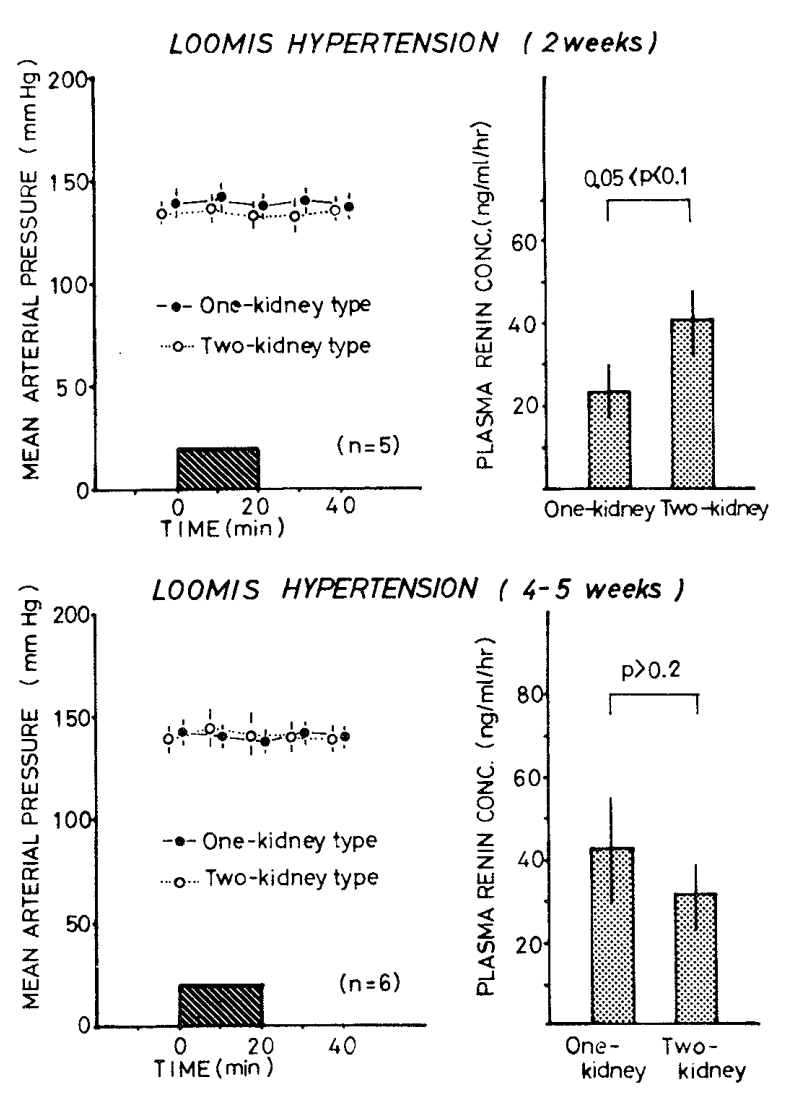

Fig.4. The effect of 1-Sar-8-Ile-A II on the blood pressure in rats with Loomis hypertension 2 weeks (upper) and 4-5 weeks (lower) after induction, and the pre-infusion level of plasma renin concentration. The hatched bars represent the infusion of the antagonist at a rate of $3.2 \mu \mathrm{g} /$ min. Open circles represent the two-kidney animals and closed circles represent the onekidney animals. Values are mean \pm S.E.

$\mathrm{n}=8$ ) and 7-8 months (BW. 260-330 g, $\mathrm{n}=$ 14), on SHRSR aged 2 months (BW. 149-168 g, $\mathrm{n}=6$ ), 5 months (BW. 270-320 g, $\mathrm{n}=6$ ), 8 months (BW. 278-348 g, $\mathrm{n}=7$ ) and 14 moths (BW. 290-366 g, $n=5$ ), and on WK rats aged 14 months (BW. 362-393 g, $n=5$ ).

Systolic blood pressure was measured by the tail plethysmographic method and those rats showing a blood pressure of $160 \mathrm{mmHg}$ or above were prepared for the experiments. Animals were fed a regular diet (Oritental, MF) and were allowed a free access to tap water except during the infusion.

Infusion of 1-Sar-8-Ile-A II Polyethylene catheters were inserted into the left jugular vein and left femoral artery under methoxy-flurane anesthesia. The catheters were filled with heparinized saline and introduced subcutaneously to the back of the neck, where their exposed parts were fixed with tape 8 Each rat was kept in an isolated cage. A few days after the cannulation, the following experiments were done on conscious animals. A blood sample $(0.4-0.5 \mathrm{ml})$ for determination of PRC was collected via the aortic catheter. The rats were harnessed and the catheters were placed in a pliable spring cable, allowing the animals to move freely. The arterial line was connected to a pressure transducer and a recorder (Nihon Koden, Japan) to trace the mean arterial pressure (MAP). The jugular vein catheter was connected to an infusion pump. Following 20-30 min recording of control blood pressure, a solution of 1-Sar-8-Ile-A II (Protein Research Foundation, Japan) was infused into the jugular vein catheter at a rate of $0.074 \mathrm{ml} / \mathrm{min}$ for $20 \mathrm{~min}$. This antagonist was dissolved in a sterile physiological saline solution in concentrations of $8.6 \mu \mathrm{g} / \mathrm{ml}$ and $43 \mu \mathrm{g} / \mathrm{ml}$. The twokidney Goldblatt rats were infused with an $8.6 \mu \mathrm{g} / \mathrm{ml}$ solution (i.e. $0.64 \mu \mathrm{g} / \mathrm{min}$ for each rat), and the other rats were infused with a $43 \mu \mathrm{g} / \mathrm{ml}$ solution (i.e. $3.2 \mu \mathrm{g} / \mathrm{min}$ ). The recording of MAP was continued for 30 min after the termination of the infusion.

Into the rats with the one-kidney Goldblatt hypertension, the rats with the one- and twokidney Loomis hypertension 4-5 weeks after induction and the 8-month-old SHRSR, none of which had exhibited significant response to the original infusion of the antagonist with above experiments, furosemide (Lasix ${ }^{\circledR}$, Hechest) was injected intraperitoneally $(50 \mathrm{mg} / \mathrm{kg})$. Two hours after the injection, the changes in body weight were checked and similar experiments were carried out again. No water was given throughout this experiment.

The effect of the infusion of 1-Sar-8-Ile-A II on the pressor action of A II (Hypertensin, Ciba) was examined in a separate experiment. Various concentrations of A II dissolved in a physiological saline were given through the femoral vein catheter to conscious normal male rats (BW. approx. $300 \mathrm{~g}, \mathrm{n}=6$ ) before and during the infusion of the antagonist ( 0.64 and $3.2 \mu \mathrm{g} / \mathrm{min})$. Determination of PRC PRC was measured according to the method described previously? A $0.1 \mathrm{ml}$ of plasma was incubated with an excess amount of rat renin substrate for $30 \mathrm{~min}$. Angiotensinase and converting enzyme activities were inhibited by the addition of EDTA, DFP and BAL. Generated angiotensin I was measured by radioimmunoassay.

Analytical Procedure The pre-infusion baseline 

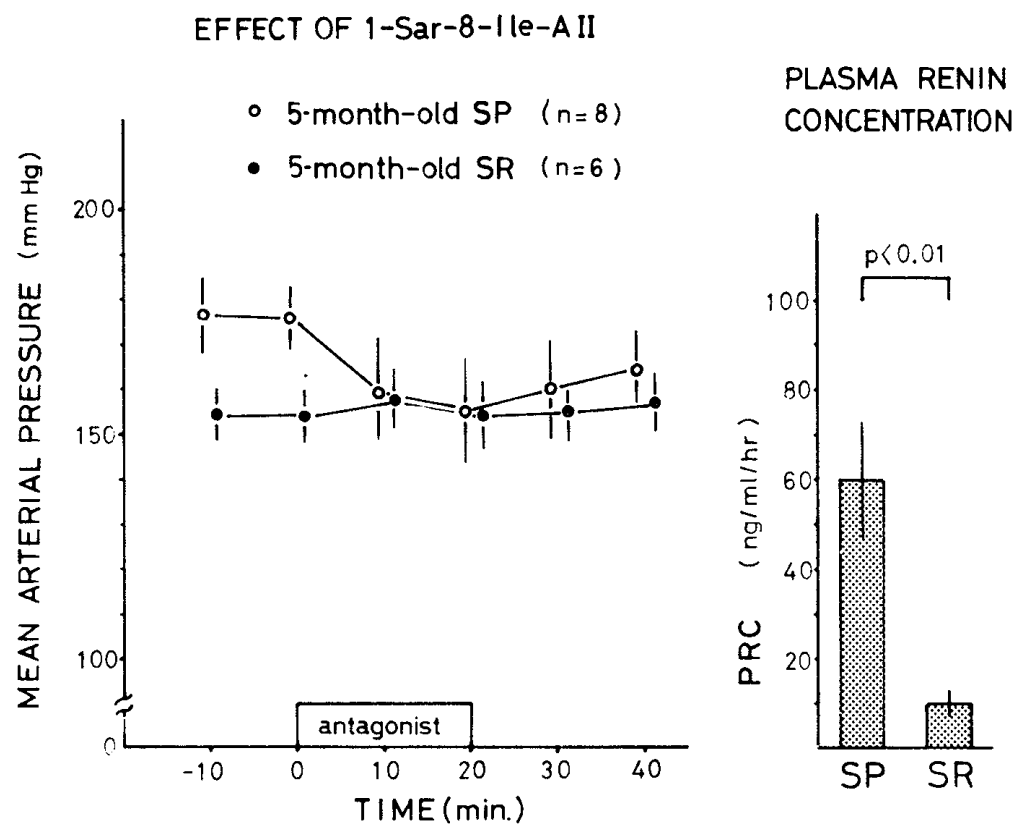

Fig.5. The effect of 1-Sar-8-Ile-A II on the blood pressure in 5-month-old strokeprone SHR and stroke-resistant SHR (left), and the pre-infusion level of piasma renin concentration (right). SP represents stroke-prone SHR and SR represents stroke-resistant SHR. The antagonist was infused at a rate of $3.2 \mu \mathrm{g} / \mathrm{min}$ into both groups. Values are mean \pm S.E.
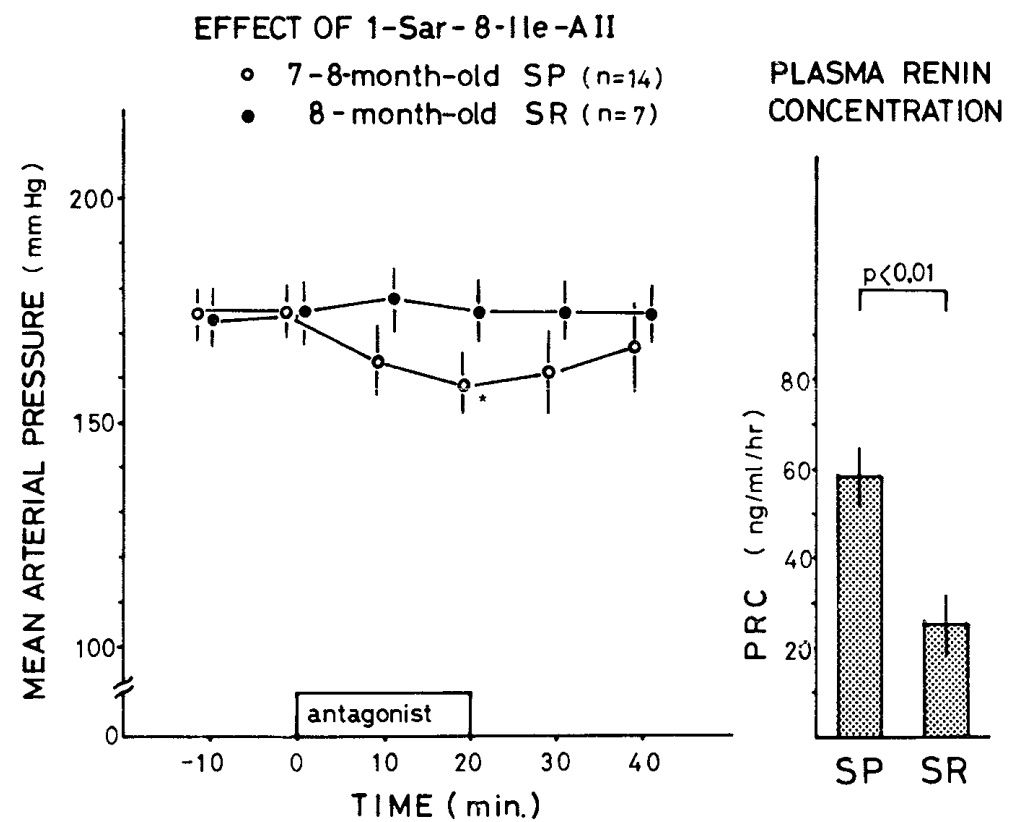

Fig.6. The effect of 1-Sar-8-fle-A II on the blood pressure in 7-8-month-old stroke-prone SHR (SP) and 8-month-old stroke-resistant SHR (SR) (left), and the pre-infusion level of plasma renin concentration (right). The antagonist was infused at a rate of $3.2 \mu \mathrm{g} / \mathrm{min}$. ${ }^{*} \mathrm{p}<0.01$, significance of difference in comparison to the control level of the mean arterial pressure. Values are mean \pm S.E.

level of MAP was directly measured on the day of the experiment. The effectiveness of the antagonist was evaluated by comparison of this base- line MAP level with the MAP level reached at the end of the infusion. Generally these two values were statistically analyzed. In terms of indivi- 

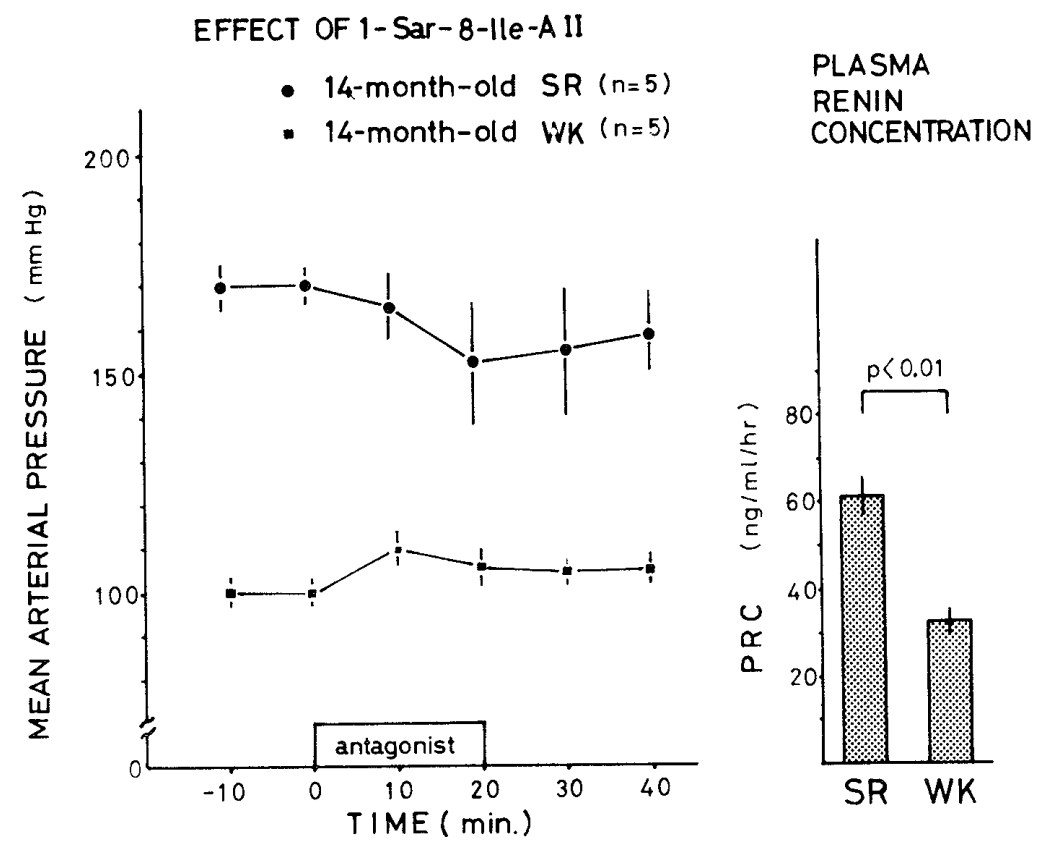

Fig.7. The effect of 1-Sar-8-Ile-A II on the blood pressure in 14-month-old strokeresistant SHR (SR) and 14-month-old Wistar Kyoto rats (WK) (left), and the preinfusion level of plasma renin concentration (right). The antagonist was infused at a rate of $3.2 \mu \mathrm{g} / \mathrm{min}$. Values are mean \pm S.E.

CORRELATION BETWEEN PRC \& THE MEAN ARTERIAL PRESSURE IN STROKE-PRONE SHR

(0 5-mo. - 7-8.mo.)

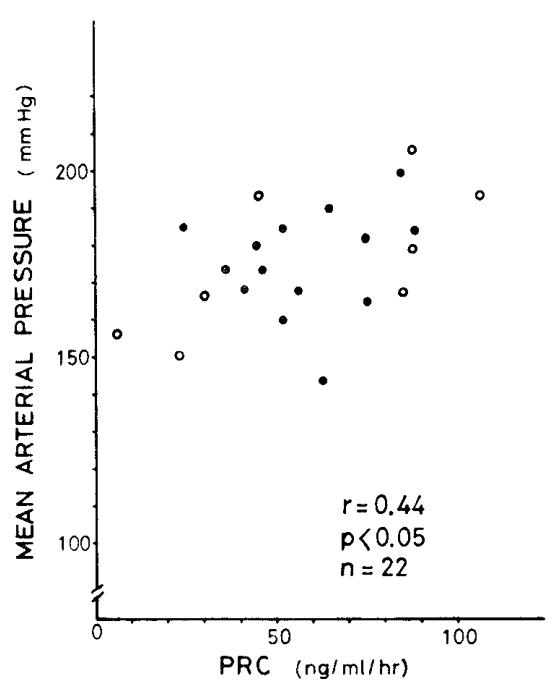

CORRELATION BETWEEN PRC \&

THE RESPONSE TO THE ANTAGONIST IN STROKE-PRONE SHR

$$
\text { (० } 5 \text {-mo. }-7-8 \cdot \mathrm{mo} \text {.) }
$$

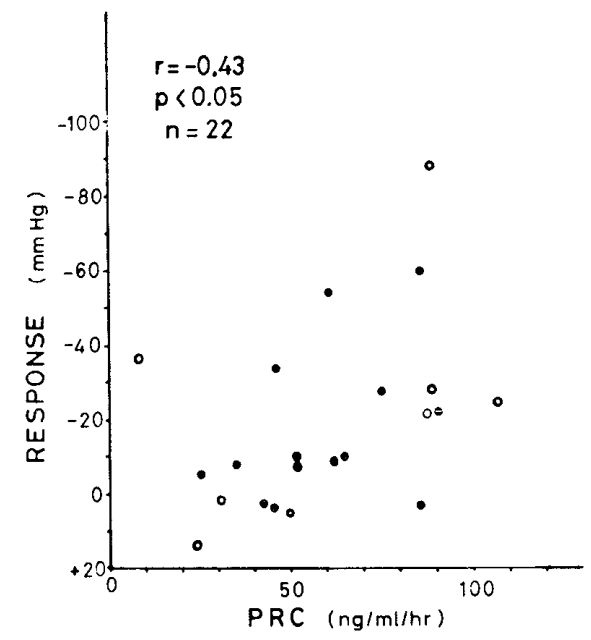

Fig.8. Correlation between the pre-infusion level of plasma renin concentration (PRC) and the mean arterial pressure (left) and between the pre-infusion PRC level and the blood pressure response to 1-Sar-8-Ile-A II (right) in stroke-prone SHR.

dual rats, a MAP decrease of $20 \mathrm{mmHg}$ or more was considered to be significant. This was based on the following observation: 1) the maximum change during the infusion of 1 -Sar-8-
Ile-A II in normal rats was within the range of $\pm 15 \mathrm{mmHg}$, and 2) the infusion of physiological saline (i.e. solvent of the antagonist) alone did not produce greater change than this range under

Japanese Circulation Journal Vol. 4I, June 1977 

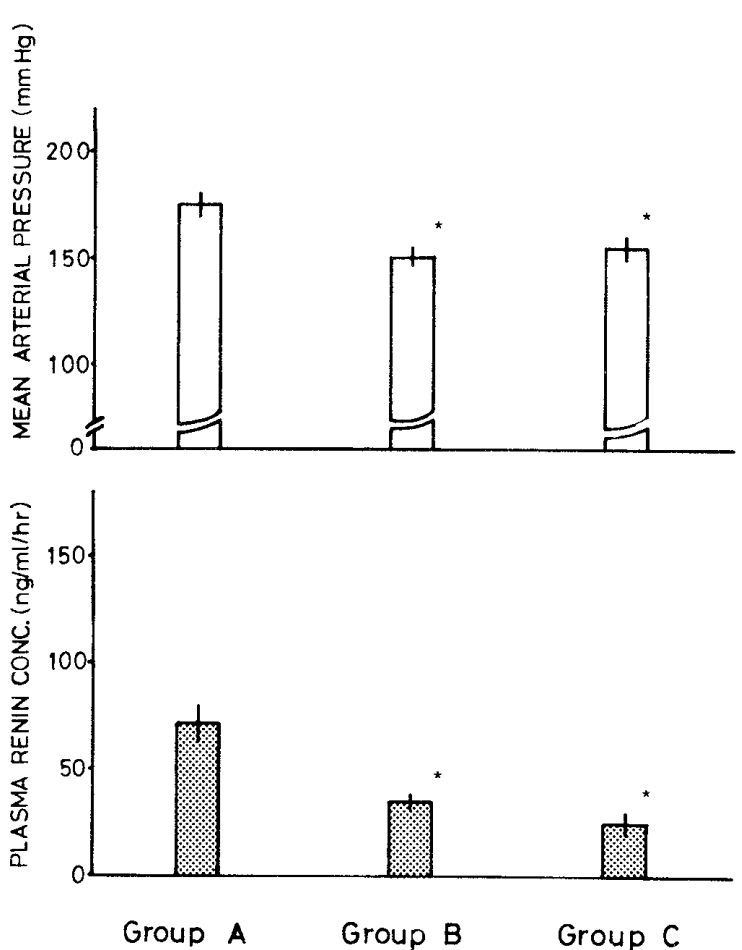

Fig.9. Mean arterial pressure and plasma renin concentration in hypertensive rats undergoing the infusion of 1-Sar-8-Ile-A II at a rate of $3.2 \mu \mathrm{g} /$ min. Group A represents the rats $(n=12)$ showing a blood pressure decrease of $20 \mathrm{mmHg}$ or more, group B represents the rats $(n=42)$ showing a blood pressure decrease of less than $20 \mathrm{mmHg}$, and group $\mathrm{C}$ represents the rats $(\mathrm{n}=$ 22) showing a blood pressure increase during the infusion of the antagonist. Details have been described in text. $* p<0.001$, significance of difference in comparison to the value of group A. Columns with brackets are mean \pm S.E. our experimental condition. The rats showing a blood pressure decrease of $20 \mathrm{mmHg}$ or more were refered to as "responder" and the others as "nonresponder".

The values were expressed as the mean \pm standard error. The significance in the difference between the experimental groups was evaluated by Student's t-test. The effects of the administration of 1-Sar-8-Ile-A II and furosemide were analyzed by Student's paired t-test.

\section{RESULTS}

Inhibition of Angiotensin II As is shown in Fig. 1, infusions of 1-Sar-8-Ile-A II(0.64 and $3.2 \mu \mathrm{g} /$ $\mathrm{min}$, i.e. 2.1 and $10.5 \mu \mathrm{g} / \mathrm{kg} / \mathrm{min}$ ) into normal rats shifted the dose-response curves for A II to the right in a dose-dependent manner.

Goldblatt Hypertension The baseline MAP (162 $\pm 10 \mathrm{mmHg})$ of the two-kidney animals $(\mathrm{n}=8)$ was almost equal to that $(160 \pm 7 \mathrm{mmHg})$ of the one-kidney animals $(n=9)$. The infusion of 1-Sar-8-Ile-A II at the dose of $0.64 \mu \mathrm{g} / \mathrm{min}(2.7-$ $3.8 \mu \mathrm{g} / \mathrm{kg} / \mathrm{min}$ ) decreased the MAP level from $160 \pm 10 \mathrm{mmHg}$ to $121 \pm 10 \mathrm{mmHg}(\mathrm{P}<0.01)$ in the two-kidney animals. On the other hand, a five-fold dosage of the antagonist $(3.2 \mu \mathrm{g} / \mathrm{min}$, i.e. $14.4-16.2 \mu \mathrm{g} / \mathrm{kg} / \mathrm{min}$ ) did not significantly change the MAP level in the one-kidney animals (Fig. 2). In terms of individual rats, there were 6 "responders" out of the 8 two-kidney rats and 2 "responders" out of the 9 one-kidney rats. The two-kidney animals had a significantly higher PRC $(161.5 \pm 40.9 \mu \mathrm{g} / \mathrm{ml} / \mathrm{hr})$ than the one-

TABLE I EFFECTS OF FUROSEMIDE

\begin{tabular}{|c|c|c|c|c|c|c|c|c|}
\hline \multirow{2}{*}{ Group } & \multirow{2}{*}{ No. } & \multicolumn{2}{|c|}{ Body weight $(g)$} & \multicolumn{2}{|c|}{$P R C(n g / m l / h r)$} & \multicolumn{3}{|c|}{ Mean Arterial Pressure $(\mathrm{mmHg})$} \\
\hline & & before & after & before & after & before & $\begin{array}{c}\text { after } \\
\text { (pre-infusion) }\end{array}$ & $\begin{array}{c}\text { infusion of } \\
\text { 1-Sar-8-Ile-A II }\end{array}$ \\
\hline $\begin{array}{l}\text { One-kidney } \\
\text { Loomis }\end{array}$ & 5 & $222 \pm 2.6$ & $206 \pm 2.5$ & $48.2 \pm 21.5$ & $136.7 \pm * * * *$ & $141 \pm 1$ & $105 \pm 7$ & $90 \pm 3$ \\
\hline $\begin{array}{l}\text { Two-kidney } \\
\text { Loomis }\end{array}$ & 5 & $227 \pm 22.0$ & $214 \pm 11.7$ & $29.2 \pm 6.4$ & $108.1 \pm 11.0$ & $138 \pm 3$ & $104 \pm \stackrel{* *}{5}$ & $89 \pm \pm^{*}$ \\
\hline $\begin{array}{l}\text { One-kidney } \\
\text { Goldblatt }\end{array}$ & 8 & $203 \pm 3.7$ & $190 \pm 4.3$ & $13.2 \pm 4.3$ & $132.2 \pm 11.7$ & $166 \pm 13$ & $143 \pm 10$ & $124 \pm 7$ \\
\hline $\begin{array}{l}\text { 8-month-old } \\
\text { SHRSR }\end{array}$ & 7 & $321 \pm 8.1$ & $303 \pm 7.6$ & $25.1 \pm 5.3$ & $84.5 \pm 7.8$ & $175 \pm 6$ & $134 \pm 4$ & $128 \pm 5$ \\
\hline
\end{tabular}

Effects of furosemide injection ( $50 \mathrm{mg} / \mathrm{kg}$, i.p.) on body weight, PRC and mean arterial pressure. Those values before and after furosemide injection are given and compared with each other. The infusion of 1-Sar-8-Ile-A II was performed on volume-depleted animals after furosemide injection, and the blood pressure level reached during its infusion was compared with the pre-infusion level. See text for details. 구 $0.05<p<0.1, \quad *_{p}<0.02, \quad * *_{p}<0.01, \quad * * * p<0.001$ 
kidney animals $(25.7 \pm 9.1 \mu \mathrm{g} / \mathrm{ml} / \mathrm{hr}$ ) (Fig. 2). A significant correlation was discovered between the pre-infusion level of PRC and the blood pressure response to the antagonist in both the onekidney model $(\mathrm{r}=-0.77, \mathrm{p}<0.05)$ and the twokidney model ( $r=-0.95, p<0.01)$ (Fig. 3). There were no significant correlation between the pre-infusion levels of PRC and MAP, nor between the MAP level and the blood pressure response to the antagonist in the both models.

Loomis Hypertension (Fig. 4). Two weeks after induction, PRC $(41.2 \pm 7.1 \mathrm{ng} / \mathrm{ml} / \mathrm{hr}, \mathrm{n}=5)$ in the two-kidney animals tended to be higher $(0.05$ $<\mathrm{p}<0.1)$ than that $(23.2 \pm 5.8 \mathrm{ng} / \mathrm{ml} / \mathrm{hr}, \mathrm{n}=5)$ found in the one-kidney animals. The baseline MAP of the one- and two-kidney animals was almost identical. Four to five weeks after induction, PRC of the one-kidney animals $(42.6 \pm 12.3$ $\mathrm{ng} / \mathrm{ml} / \mathrm{hr}, \mathrm{n}=6$ ) was not significantly different from that of the two-kidney animals $(31.6 \pm 6.3$ $\mathrm{ng} / \mathrm{ml} / \mathrm{hr}, \mathrm{n}=6)$. The MAP level of these two groups was almost equal $(142 \pm 4 \mathrm{mmHg}$ and 143 $\pm 3 \mathrm{mmHg}$, respectively), and was significantly higher than that of the sham-operated controls $(100 \pm 2 \mathrm{mmHg})$. The infusion of 1-Sar-8-Ile-A II $(3.2 \mu \mathrm{g} / \mathrm{min}, 12.3-16.7 \mu \mathrm{g} / \mathrm{kg} / \mathrm{min})$ produced no significant reduction in MAP in any groups. There was no responder. No significant correlation was observed between the pre-infusion level of PRC and the blood pressure response to the antagonist, and between PRC and MAP.

SHRSP, SHRSR and WK rats. Two-month-old

SHRSR had an elevated MAP already $(127 \pm 2$ $\mathrm{mmHg})$, while they had normal PRC $(11.5 \pm 2.8$ $\mathrm{ng} / \mathrm{ml} / \mathrm{hr})$. The infusion of 1-Sar-8-Ile-A II (3.2 $\mu \mathrm{g} / \mathrm{min}, 18.9-21.3 \mu \mathrm{g} / \mathrm{kg} / \mathrm{min}$ ) changed the MAP level from $127 \pm 2 \mathrm{mmHg}$ to $136 \pm 5 \mathrm{mmHg}$ (not significant). At the age of 5 months, PRC of SHRSP was high $(59.3 \pm 13.2 \mathrm{ng} / \mathrm{ml} / \mathrm{hr})$, whereas that of SHRSR was within normal range (10.0 \pm $2.5 \mathrm{ng} / \mathrm{ml} / \mathrm{hr}$ ), and the difference was significant $(\mathrm{p}<0.01)$. MAP of SHRSP was $176 \pm 7 \mathrm{mmHg}$, significantly higher $(p<0.01)$ than that of SHRSR (154 $\pm 5 \mathrm{mmHg})$. The infusion of the antagonist reduced the MAP from $176 \pm 7 \mathrm{mmHg}$ to $155 \pm 12 \mathrm{mmHg}$ in SHRSP (NS. $0.1<\mathrm{p}<$ 0.2 ). Individually, there were 4 "responder" rats out of the 8 subjects. In the case of SHRSR, the antagonist did not significantly alter the MAP, and there was no "responder" present. Seven to eight-month-old SHRSP had significantly $(p<$ $0.01)$ higher PRC $(58.7 \pm 5.7 \mathrm{ng} / \mathrm{ml} / \mathrm{hr})$ than the 8-month-old SHRSR $(25.1 \pm 5.6 \mathrm{ng} / \mathrm{ml} / \mathrm{hr})$. MAP of SHRSP and SHRSR was almost equal (175 \pm 4
$\mathrm{mmHg}$ and $175 \pm 5 \mathrm{mmHg}$, respectively). The infusion of the antagonist changed the MAP from $175 \pm 4 \mathrm{mmHg}$ to $158 \pm 6 \mathrm{mmHg}(\mathrm{p}<0.01)$ in the 7-8-month-old SHRSP, while it did from 175 $\pm 5 \mathrm{mmHg}$ to $175 \pm 6 \mathrm{mmHg}$ (NS) in the 8month-old SHRSR. Five "responder" rats were found in the SHRSP group, but none in the SHRSR group. At the age of 14 months (Fig. 7), PRC of SHRSR was elevated $(61.6 \pm 4.2 \mathrm{ng} / \mathrm{ml} /$ $\mathrm{hr})$, and significantly higher $(\mathrm{p}<0.001)$ than that of $W K$ rats $(32.1 \pm 3.0 \mathrm{ng} / \mathrm{ml} / \mathrm{hr})$. MAP of SHRSR $(170 \pm 4 \mathrm{mmHg})$ was also significantly higher $(p<0.001)$ than that of WK rats $(102 \pm 2$ $\mathrm{mmHg}$ ). The antagonist changed the MAP from $170 \pm 4 \mathrm{mmHg}$ to $153 \pm 15 \mathrm{mmHg}$ in the SHRSR group (NS), and from $102 \pm 2 \mathrm{mmHg}$ to $107 \pm 3$ $\mathrm{mmHg}$ in the WK group (NS). There was one "responder" SHRSR which had a moderately increased PRC $(51.6 \mathrm{ng} / \mathrm{ml} / \mathrm{hr})$ and showed a marked fall in MAP (from $180 \mathrm{mmHg}$ to 100 $\mathrm{mmHg}$ ).

There was a significant correlation between the pre-infusion level of PRC and the blood pressure response to the antagonist $(\mathrm{r}=-0.43$, $\mathrm{p}<0.05, \mathrm{n}=22)$ and between PRC and the baseline level of MAP $(r=0.44, p<0.05, n=22)$ (Fig. 8) in all of SHRSP. Such a relationship was not observed in the SHRSR group.

"Responder" and "Non-responder" The hypertensive rats other than the two-kidney Goldblatt rats were divided into three groups, based on the responsiveness to the infusion of the antagonist $(3.2 \mu \mathrm{g} / \mathrm{min})$. The two-kidney Goldblatt rats were not included here because they were infused with the lower dose of the antagonist (0.64 $\mu \mathrm{g} / \mathrm{min}$ ). These three were Group A showing a MAP decrease of $20 \mathrm{mmHg}$ or more $(n=13)$, Group B showing a MAP decrease of less than $20 \mathrm{mmHg}(\mathrm{n}=42)$ and Group $\mathrm{C}$ showing a MAP increase $(n=22)$ as was shown in Fig. 9. PRC of Group A $(71.0 \pm 7.2 \mathrm{ng} / \mathrm{ml} / \mathrm{hr})$ was significantly higher $(\mathrm{p}<0.001)$ than that of Groups B and C $(33.9 \pm 3.2 \mathrm{ng} / \mathrm{ml} / \mathrm{hr}$ and $25.2 \pm 4.6 \mathrm{ng} / \mathrm{ml} / \mathrm{hr})$, respectively). The MAP level of Group A (178 \pm $5 \mathrm{mmHg})$ was also significantly higher $(\mathrm{p}<$ $0.001)$ than that of Group B and C (153 \pm 3 $\mathrm{mmHg}$ and $156 \pm 5 \mathrm{mmHg}$, respectively). No significant difference was observed in PRC and MAP between Group B and C.

Effects of Furosemide Data were summarized in Table I. Furosemide significantly decreased the body weight and markedly increased PRC in all of the groups. The decrease in MAP caused by furosemide was significant $(p<0.001)$ in the 
one- and two-kidney Loomis rats and SHRSR, but was not significant $(0.05<\mathrm{p}<0.1)$ in the one-kideny Goldblatt rats. The infusion of the antagonist $(3.2 \mu \mathrm{g} / \mathrm{min})$ following the injection of furosemide produced a significant fall $(\mathrm{p}<$ $0.02)$ in MAP in the three groups, while it did not significantly $(0.05<\mathrm{p}<0.1)$ in the SHRSR group. There was no correlation between PRC and MAP nor between PRC and the blood pressure response to the antagonist in any group.

\section{DISCUSSION}

There was some evidence to indicate that the plasma renin level of rats was easily affected by various stimuli, 10 and that the effect of A II inhibitors varied due to the anesthesia!1 Use of anesthetic agents tends to have provided a misleading conclusion in the field of the renin and angiotensin studies on experimental hypertension of rats. In the present experiment, plasma renin level and the effect of 1-Sar-8-Ile-A II were investigated under an unanesthetized, minimally stressed condition. It was confirmed that 1-Sar8-Ile-A II antagonized the pressor action of exogenously administered A II in a dose-dependent manner and the dosages used herein were able to block the pressor action of a large amount of A II (Fig. 1). Pettinger et al. showed that the stable plasma concentration of 1-Sar-8Ala-A II, a little different antagonist, was achieved within less than 20 min after the start of its infusion. ${ }^{2}$ Therefore, the degree of the contribution of the vascular action of A II would be appraisable based on the hypotensive effect of 20 min infusion of 1-Sar-8-Ile-A II.

Though Goldblatt hypertension has been the subject of many extensive studies, the precise role of the renin-angiotensin system remains undetermined. Brunner et al. studied the rats with Goldblatt hypertension of 6 week duration and observed that the infusion of 1-Sar-8-Ala-A II reduced blood pressure in the two-kidney model, but not in the one-kidney model.13 On the other hand, Bumpus et al. reported that 8-Ile-A II $(0.2 \mu \mathrm{g} / \mathrm{min})$ was effective in the twokidney rats (6 weeks after clipping), but not in the one-kidney rats (4-6 weeks after clipping), and that its five-fold dosage was required in lowering the blood pressure of the latter model? These experiments of both authors were done on anesthetized animals. Bing and Nielsen found that 1-Sar-8-Ala-A II exerted the hypotensive effect in both anesthetized and conscious rats with one- and two-kidney hypertension and that the larger dose was often required in the onekidney model $!^{11}$ Though these reports seem to suggest that the two types of Goldblatt hypertension differ in the susceptibility to A II antagonists, the plasma renin level has not been measured and the relationship between the plasma renin level and the susceptibility to antagonists have not been evaluated. The results of the present experiments of Goldblatt hypertension demonstrated that the two-kidney animals had significantly higher PRC levels and greater susceptibility to the antagonist than the one-kidney animals. Our Goldblatt hypertension of 4-5 week duration after clipping was somewhat of a shorter duration as compared with those of Brunner and Bumpus. Our results were generally compatible with the reports of other investigators $3,13,14$ In terms of individual rats, there were "responders" in the one-kidney group and "non-responders" in the two-kidney group. "Responders" tended to have higher PRC than "non-responders" in both groups. On the other hand, a significant correlation was discovered between the pre-infusion level of PRC and the blood pressure response to the antagonist in both groups. These relationships suggest that the susceptibility to the antagonist was related to the plasma renin level in both models. Recently, Macdonald et al. investigated plasma renin activity (PRA) and the hypotensive effect of 1-Sar-8Ala-A II on conscious rats with two-kidney Goldblatt hypertension of various time duration, and demonstrated that the blood pressure response to this antagonist significantly correlated with the level of PRA prevailing immediately before the infusion. 15 Their experimental procedure and results were essentially the same as ours. Collectively, our results indicated that the renin angiotensin system was largely involved in the two-kidney hypertension, while it was of much lesser degree involved in the one-kidney hypertension. The way in which renin and angiotensin II participated was complicated, because 1) no correlation was found between the level of PRC and the degree of hypertension in both models, and 2) the administration of the antagonist did not always normalize the blood pressure even in the two-kidney model.

Little-written evidence is available on the pathogenesis of Loomis hypertension following renal segmental infarction?,16,17 In the present experiment, the two different types of this hypertension were induced to verify a possible difference in the role of the renin angiotensin 
system as found in Goldblatt hypertension. The blood pressure level of the one-kidney group was almost equal to that of the two-kidney group. There was no significant difference in PRC between the two groups, although PRC of the two-kidney group tended to be higher than that of the one-kidney group 2 weeks after induction. The level of PRC varied considerably, and one rat showed a high PRC $(91.5 \mathrm{ng} / \mathrm{ml} / \mathrm{hr})$, the value almost comparable to that found in "responders" in Goldblatt hypertension. Nonetheless, the antagonist was ineffective for any group, and no "responder" existed in any of our Loomis rats. Therefore, even if increased renin level was detected, it could not be said that plasma A II contributed to the maintenance of our Loomis hypertension. There was no correlation between PRC and the blood pressure response to the antagonist, nor between PRC and MAP. MAP did not also correlate with the blood pressure response to the antagonist. One might think that our Loomis animals were not so hypertensive, but their MAP levels were significantly higher than the controls'. Accordingly, the inability of the antagonist seemed to be unrelated to the blood pressure level in Loomis hypertension. Thus, our results suggest that the renin-angiotensin system was not responsible for the established stage of Loomis hypertension regardless of the presence or absence of the contralateral kidney. This view is in keeping with some earlier works, ${ }^{16,17}$ but it contradicts the suggestion of Ebihara ${ }^{18}$ who stated that the renin-angiotensin system participated in the pathogenesis of Loomis hypertension, since the renin content was increased in the area adjoining the infarcted part of the kidney. But the total renin content of the kidney was not increased and the plasma renin level was not measured in his experiment.

Recently, the stroke-prone strain of the spontaneously hypertensive rats (SHRSP) was separated by the succesive selective breeding? SHRSP developed severe hypertension rapidly and over $80 \%$ of them died of strokes (cerebral bleeding and/or softening) within 10 months of age. In contrast, stroke-resistant SHR (SHRSR) had a more chronic course of hypertension and a lower incidence of strokes (less than 7\%). Thus SHRSP is an excellent model for studies on malignant hypertension. Matsunaga, et al. revealed that young SHRSP had normal levels of PRC, while older SHRSP (at and after 7 months of age) had significantly elevated levels of PRC, which were always associated with malignant vascular lesions in both of the brain and the kidney? In the present experiment, PRC of SHRSP was significantly higher than that of SHRSR at 5 and 7-8 months of age. Highrenin SHRSP displayed the distinct vascular lesions including angionecrosis in the kidney. I-Sar-8-Ile-A II did not significantly $(0.05<$ $p<0.1)$ decrease the blood pressure in the 5 -month-old SHRSP, but significantly $(\mathrm{p}<$ 0.01 ) decreased the blood pressure in the 7-8month-old SHRSP. There was a significant correlation between the pre-infusion level of PRC and the blood pressure response to the antagonist, and between PRC and MAP in the whole of SHRSP. The MAP level reached during the infusion remained above normal. Collectively, these results suggest that the reninangiotensin system contributed to the maintenance of the advanced and malignant stages of hypertension in SHRSP, although it did not totally account for the mechanism for hypertension. These findings are comparable to those in human malignant hypertension where elevated renin levels and angiotensin-II dependency of blood pressure are manifested. It is worth to note that contributing factors of the maintenance of hypertension alter with increasing age and progression of hypertension.

Matsunaga et al. described that the PRC levels of SHRSR were not different from those of the WK controls from 7 weeks to 12 months of age? The present experiment confirmed these previous observation, while SHRSR had significantly higher PRC than the controls at 14 months of age. The variation of PRC was relatively small. 1-Sar-8-Ile-A II failed to induce a significant change of blood pressure in any agegroups. The pre-infusion level of PRC did not correlate with the baseline MAP and with the blood pressure response to the antagonist. Therefore, statistically speaking, the renin-angiotensin system seemed to play no essential role in the maintenance of hypertension in SHRSR. This is consistent with earlier work of Pals et al., indicating that 1-Sar-8-Ala-A II had no hypotensive effect in conscious SHR $(250-300 \mathrm{~g}$, age undescribed). The other studies with a converting enzyme inhibitor offered a similar evidence? ${ }^{20}$ It is of interest that the 14-month-old SHRSR had higher PRC and one of them exhibited a marked fall during the infusion of the antagonist. The possibility could not be denied that the renin-angiotensin system would have a role in the hypertension of much older SHRSR, as found in 


\section{SHRSP.}

The interaction of the sodium status to the function of the renin-angiotensin system has aroused much interest. Gavras et al. stated that chronic one-kidney Goldblatt rats responded to 1-Sar-8-Ala-A II when they were sodium-depleted by the feeding of a low sodium diet (plasma renin levels were not measured) ${ }^{21}$ In the present study, the administration of furosemide significantly decreased the body weight and increased PRC in all of the four groups (Table I). The rate of increase in PRC was most prominent in the one-kidney Goldblatt rats, which had showed a low level of PRC prior to the injection of furosemide. PRC reached to a similar level except in the 8-month-old SHRSR group, of which the response was somewhat less than that of the other three groups. These results of the SHRSR experiment were dissimilar to those of Forman et al.,22 who indicated that low sodium diet did not stimulate PRA in old SHR (6-8 months of age), though the test system used was different. The effect of furosemide on the blood pressure was significant except in the one-kidney Goldblatt group. Judging from the change of body weight and PRC, our all animals of the 4 goups probably had an acute volume-depletion, although the blood volume was not measured. Little hypotensive effect of furosemide in the one-kidney Goldblatt group would be explainable by the view that the vasoconstricting factor (A II) replaced the volume factor in maintaining blood pressure, since angiotensin-II dependency of blood pressure was proven in a volumedepleted state. Similarly, volume-depletion disclosed angiotensin-II dependency in the one- and two-kidney Loomis hypertension. However, the volume-depleted 8-month-old SHRSR were less $(0.05<\mathrm{p}<0.1)$ susceptible to the antagonist. The pre-infusion level of blood pressure appeared to be not a determinant, because the other three groups responded to the antagonist in spite of the various blood pressure level. Evidence has indicated that structural changes in resistance vessels occurred in an early phase of hypertension and contributed to the maintenance of the established hypertension in SHR ${ }^{23}$ The 8-month-old SHRSR with a long-lasting hypertension could well suffer such vascular changes. By contrast, the other three groups with a short-lasting hypertension could not. This might explain the difference in the susceptibility to the antagonist in a volume-depleted state. There was no significant correlation between PRC and MAP, and between PRC and the responsiveness to the antagonist in all the groups. Thus, the interrelationship between renin-intiating vasoconstricting factor (A II) and the volume factor was not so simple, and these two factors could not fully account for the mechanism of maintenance of hypertension. Other factors, such as vascular factors, should be involved in the hypertensive process.

In the present study, a significant correlation between the pre-infusion level of PRC and responsiveness to the infusion of 1-Sar-8-Ile-A II was noticed in Goldblatt and SHRSP hypertension, but not in Loomis and SHRSR hypertension. These results were different from those of Pals et $\mathrm{al}^{24}$ who indicated that the effect of 1-Sar-8-Ala-A II in a conscous dog was directly proportional to the magnitude of PRA regardless of the type or duration of hypertension. On the other hand, "responders" tended to show higher PRCs than "non-responders" in each hypertensive group, but the difference was not significant except in the SHRSP group. When the various groups of rats infused with the antagonist at $3.2 \mu \mathrm{g} / \mathrm{min}$ were considered as a whole, "responders" showed significantly higher PRCs than "non-responders". This is in an agreement with the study of Macdonald et al. on two-kidney Goldblatt rats. ${ }^{15}$ Therefore, it could be said that the responsiveness to the antagonist appeared to be of a some degree renin-related. However, the PRC levels overlapped considerebly between "responders" and "non-responders", and the difference was not so clear-cut. Actually, there were high-renin "nonresponders", of which the highest PRC level was $91.5 \mathrm{ng} / \mathrm{ml} / \mathrm{hr}$. In contrast, there was only one "responder" with a low PRC level $(6.3 \mathrm{ng} / \mathrm{ml} / \mathrm{hr})$, and the other "responders" showed the PRC level of higher than $46.3 \mathrm{ng} / \mathrm{ml} / \mathrm{hr}$. Since plasma A II concentration has not been measured in this study, plasma A II level might not parallel PRC level under our experimental condition. Concerning the MAP level, a significant difference was also found between "responders" and "nonresponders" (Fig. 9), though it was not found in each experimental group. The absence of significant difference between PRC and MAP in most of the groups would be largely due to a small number of rats in each. PRC and MAP of rats showing a blood pressure decrease of less than $20 \mathrm{mmHg}$ were not different from those of rats showing a blood pressure increase (less than $20 \mathrm{mmHg}$ ). Therefore, the blood pressure 
response within $\pm 20 \mathrm{mmHg}$ might be included in the spectrum of one population, though 1-Sar8-Ile-A II exerted an variable effect of blood pressure. In any case, the pressor activity of the antagonist complicated the interpretation of the data. Use of antagonist devoid of an agonistic property will be necessary.

\section{Acknowledgements}

Thanks are tendered to Drs. M. Matsunaga and $A$. Hara for their collaboration and suggestion, to Assist. Prof. K. Ogino and Prof. C. Kawai for their advice and criticism, and to Prof. Y. Yamori of the department of pathology, Shimane University school of medicine, for generous supply of SHR. Thanks are also due to Dr. H. Kambara for assistance with the manuscript.

\section{REFERENCES}

1. DAVIS, J. O., FREEMAN, R. H., JOHNSON, J. A., \& SPIELMAN, W. S.: Agents which block the action of the renin angiotensin system. Circulation Res. 34: 279, 1974.

2. TÜRKER, R. K. HALL, M. M., YAMAMOTO, M., SWEET, C. S., \& BUMPUS, F. M.: A new, longlasting competitive inhibitor of angiotensin. Science 177: 1203, 1972.

3. BUMPUS, F. M., SEN, S., SMEBY, R. R., SWEET, C. S., FERRARIO, C. M., \& KHOSLA, M. C.: Use of angiotensin II antagonists in experimental hypertension. Circulation Res. 32 and 33 (Suppl. 1): $150,1973$.

4. YAMAMOTO, J., MATSUNAGA, M., HARA, A., PAK., C., KIRA, J., OGINO, K., \& KAWAI, C.: Plasma renin and the antihypertensive effect of angiotensin II antagonist in experimental hypertension. Jap. Circulation J. 40: 895, 1976.

5. YAMAMOTO, J., MATSUNAGA, M., HARA, A., YAMORI, Y., OGINO, K., \& KAWAI, C.: The role of the renin-angiotensin system in the spontaneously hypertensive rat. Clin. Exp. Pharmacol. Physiol (Suppl. 3): 195, 1976.

6. LOOMIS, D.: Hypertension and necrotizing arteritis in the rat following renal infarction. Arch. Pathol. 41: 231, 1946.

7. OKAMOTO, K., YAMORI, Y., \& NAGAOKA, A.: Establishment of the stroke-prone spontaneously hypertensive rat. Circulation Res. 34 and 35 (Suppl. I): 143, 1974.

8. MATSUNAGA, M., KOMURO, T., YAMAMOTO, J., HARA, A., OGINO, K., YAMORI, Y., \& OKAMOTO, K.: Plasma renin, water and electrolyte balance, and vascular complications in SHR. Jap. Circulation J. 40: 889, 1976.

9. MATSUNAGA, M., YAMAMOTO, J. HARA, A., YAMORI, Y., OGINO, K., \& OKAMOTO, K.: Plasma renin and hypertensive vascular complications; an observation in the stroke-prone spontaneously hypertensive rat. Jap. Circulation J. 39: $1305,1975$.

10. CARABAlho, J., Shapiro, R., HOPPER, P.,
\& PAGE, L. B.: Methods for serial study of renin angiotensin system in the unanesthetized rat. $\mathrm{Am}$. J. Physiol. 228: 369, 1975.

11. BING, J. \& NIELSEN, K.: Role of the reninsystem in normo- and hypertension. Acta. Pathol. Microbial. Scand. Section A. 81: 254, 1973.

12. PETTINGER, W. A., KEETON, K. PHiL, M., \& TANAKA, K.: Radioimmunoassay and pharmacokinetics of saralasin in the rat and hypertensive patients. Cli. Pharmacol. Therap. 17: 146, 1975.

13. BRUNNER, H. R., KIRSHMAN, J. D., SEALY, J. E., \& LARAGH, J. M.: Hypertension of renal origin; evidence for two different mechanisms. Science 174: 1344, 1971.

14. KRIEGGER, E. M., SALGADO, H. C., ASSAN, C. J., GREENE, L. L. J., \& FERREIRA, S. H.: Potential screening test for detection of overactivity of renin-angiotensin system. Lancet 1: $269,1971$.

15. MACDONALD, G. J., BOYD, G. W., \& PEART, W. S.: Effect of the angiotensin II blocker 1-Sar8-Ala-Angiotensin II on renal artery clip hypertension in the rat. Circulation Res. 37: 640, 1975.

16. OMAE, T., MASSON, G. M. C., \& PAGE, I. H.: Release of renin in hypertensive rats. Am. $J$. Physiol. 199: 637, 1960.

17. SOKABE, H. \& GROLLMAN, A.: A study of hypertension in the rat induced by infarction of the kidney. Texas Rep. Biol. Med. 21: 93, 1963.

18. EBIHARA, A.: Studies on the pathogenesis of experimental hypertension in the rats. Jap. Circulation J. 36: 603, 1972.

19. PALS, D. T., MASUCCI, F. D., DENNING, G. S., Jr., SIPOS, F., \& FESSLER, D. C.: Role of the pressor action of angiotensin II in experimental hypertension. Circulation Res. 29: 673, 1971.

20. BIANCHI, A., EVANS, D. B., COBB, M., PESCHKA, M. T., SCHAEFFER, T. R., \& LAFFAN, R. J.: Inhibition of SQ 20881 of vasopressor response to angiotensin in conscious animals. Eur. J. Pharmacol. 23: 90, 1973.

21. GAVRAS, H., BRUNNER, H. R., VAUGHAN, E. D., \& LARAGH, J. H.: Angiotensin-sodium interaction in blood pressure maintenance of renal hypertensive and normal rats. Science 180: 1369, 1973.

22. FORMAN, B. H. \& MULROW, P. J.: Effect of propranolol on blood pressure and plasma renin activity in the spontaneously hypertensive rat. Circulation Res. 35: 215, 1974

23. KYOGOKU, M., HAEBARA, H., OOSHIMA, A., YAMORI, Y., IKEHARA, S. OHTA, T., OKUDA, T., \& OKAMOTO, K.: Further studies on the cardiovascular system in the spontaneously hypertensive rat. In Spontaneous Hypertension (ed. by Okamoto, K.) Springer-Igaku Shoin, New York, Berlin and Tokyo, p. 155, 1972.

24. PALS, D. T. \& MASUCCI, F. D.: Plasma renin and the antihypertensive effect of 1-Sar-8-Ala-angiotensin II. Europ. J. Pharmacol. 23: 115, 1973. 